\title{
Identifying and Characterizing Children of Parents with a Serious Illness Using Survey and Register Data
}

This article was published in the following Dove Press journal: Clinical Epidemiology

\author{
Sanne Ellegård Jørgensen' \\ Susan I Michelsen' \\ Anette Andersen ${ }^{2}$ \\ Janne S Tolstrup' \\ Lau C Thygesen'
}

'National Institute of Public Health, University of Southern Denmark, Copenhagen, I455, Denmark; ${ }^{2}$ Steno Diabetes Center Aarhus, Aarhus University Hospital, Aarhus N, 8200, Denmark
Correspondence: Sanne Ellegård Jørgensen

University of Southern Denmark, Studiestræde 6, Copenhagen, I455,

Denmark

Tel + 004565507844

Email saej@sdu.dk
Purpose: To estimate the prevalence and characterize children and adolescents aged 0-21 years with a physically or mentally ill parent based on registers. Further, to explore the use of register and survey data to identify parental serious illness.

Methods: The study is based on: 1) a 20\% register sample of children and adolescents aged 0-21 in 2014; and 2) survey data from the Danish Youth Profile 2014 including 63,437 youth education students linked to registers. In registers, parental physical illness comprised hospital diagnoses included in the Charlson Comorbidity Index, and parental mental illness encompassed all mental diagnosis in the registers. Information about socioeconomic and demographic characteristics and use of health care services was retrieved from national registers. In the survey, students were asked if they had experienced serious illness of a parent.

Results: In the register sample of 0-21-year-olds, $25.3 \%$ had a parent with a physical or mental diagnosis, the prevalence increasing with age of the child. Compared to children without parental illness, children with an ill parent more frequently had unemployed parents, lower parental educational level, and a chronic medical condition. Analyses of the discrepancies between register and survey data revealed that $9 \%$ of the adolescents were identified as having an ill parent in both data sources and $64.1 \%$ had no identified ill parents. Moreover, a higher frequency of parental primary health care service use was seen for adolescents with an ill parent, across identification method, indicating that both methods identify adolescents with an ill parent.

Conclusion: The social inequality and elevated frequency of health problems among children and adolescents with an ill parent, underline the vulnerability of this population. Parental illness can be identified from both parental hospital diagnoses as well as selfreported by adolescents, however the two methods detect different populations. Both methods have several limitations and would benefit from further refinement and validation.

Keywords: parental illness, childhood adversity, characteristics, register data, survey data, social inequality

\section{Introduction}

Parental illness may affect the emotional, social, and behavioral development of the children, ${ }^{1}$ and have been shown to increase the risk of problem behavior and mental health problems of the offspring. ${ }^{2-6}$ Knowing the prevalence and characteristics of children affected by serious parental illness is central in developing adequate interventions, raise awareness, and dimension resources for those with the greatest needs. However, the prevalence and characteristics of children experiencing 
parental illness in Denmark is largely unknown. A Finnish study indicates that $6.6 \%$ of children under the age of 21 have a parent with cancer, ${ }^{7}$ while a German national survey found a prevalence of $4.1 \%$ for parental somatic illness and $2.3 \%$ for parental mental illness among families with 4- to 18-year-old offspring. ${ }^{8}$ A Swedish register-based cohort study estimated that $9.8 \%$ had a physically ill parent and $6.4 \%$ had a mentally ill parent. ${ }^{9}$ Physical parental illness was defined by hospitalization for at least seven days with a non-psychiatric disorder and mental parental illness as hospitalization for at least one day with a psychiatric disorder, the hospitalization occurring after the child's graduation from primary school. A recent register-based study estimated that one in four children in the UK experienced maternal mental illness during their childhood, the prevalence increasing with age. ${ }^{10}$ An American study estimated that $3.8 \%$ of parents had a serious mental illness (schizophrenia, bipolar disorder, and major depression) and $18.2 \%$ had any mental illness based on the past year prior to the time of estimation. ${ }^{11}$ Thus, great variation in the prevalence of parental illness exists between studies, possibly explained partly by variation in definitions of and methods used for identification of parental illness.

Studies characterizing children with ill parents are also lacking. A Dutch study, including adolescents aged 10-20 years, compared children with and without a chronically ill parent. ${ }^{12}$ The authors found no difference in relation to parental education; however, the employment status differed from $63.5 \%$ in families with an ill parent to $91.1 \%$ in the comparison group, and adolescents in families with an ill parent had a significantly lower family income. ${ }^{12}$ In a register-based study among Danish children, Moberg et al (2017) found no difference in the educational level of parents with multiple sclerosis and parents without. ${ }^{13} \mathrm{In}$ relation to parental mental illness, studies have shown socioeconomic differences between parents with and without mental illness, for instance lower socioeconomic classification at birth of the child ${ }^{14}$ and higher frequency of unemployment. ${ }^{15}$ Moreover, studies have shown that children with a mentally ill parent more often live in singleparent homes, compared to children without a mentally ill parent. ${ }^{14,15}$

Considering the steady increase in the prevalence of chronic diseases, ${ }^{16}$ the number of children affected by parental illness is likely to increase. To our knowledge, no accurate picture of the prevalence and characteristics of children affected by parental illness in Denmark is available.

The aims of the present study were to:

(I) Estimate the proportion of children and adolescents aged 0-21 years who have a parent with a serious or chronic, mental or physical illness, using national registers.

(II) Characterize children and adolescents aged 0-21 years with and without an ill parent in relation to socioeconomic background, migration status, family structure, and serious or chronic medical conditions of the child, using register data.

(III) Explore the discrepancy between parental illness identified in registers and surveys among a subsample of adolescents aged 15-25 years; furthermore, explore the differences in characteristic, patterns in reporting of diagnoses, and patterns in use of health care services between children with parental illness identified in registers, survey, and both in registers and survey.

\section{Materials and Methods}

\section{Data Sources and Study Population}

This study is based on two data sources: 1) a random registers sample of $20 \%$ of all Danish children born from 1993 to 2013; and 2) survey data from the Danish National Youth Study 2014, linked to registers. ${ }^{17}$

\section{Register Sample}

Denmark has many national registers containing highquality data on a range of health outcomes as well as living conditions, and socioeconomic and demographic information. All Danish residents have a unique personal identification number, which allows combining information from different registers on an individual level. ${ }^{18}$ In this study, we used data from several national registers to obtain information about health, socioeconomic position, migration status, and illnesses among children and parents. The study population consisted of a $20 \%$ sample of all children born between Jan 1, 1993 and Dec 31, 2013, alive and residing in Denmark by January 1, 2014 retrieved from the National Civil Registration System. ${ }^{19}$ This resulted in 279,274 children aged 0-21 years by September 2014. The Danish Civil Registration System and the unique personal identification number of children and parents were used to match legal parents and children. ${ }^{19}$ 


\section{The Danish National Youth Study 2014}

The Danish National Youth Study 2014 included 70,674 students attending high school and 5179 attending vocational schools, response rates were $84.8 \%$ and $68.8 \%$, respectively. ${ }^{17}$ The questionnaire comprised questions about wellbeing, health, and risk behavior, and data collection took place in 2014. The electronic questionnaire was completed during class hours with a teacher present and available for questions. A more detailed description of the Danish National Youth Study 2014 is reported elsewhere. ${ }^{17}$ For $98 \%$ of the adolescents, the unique personal identification number was available. This article included students who participated in the Danish National Youth Study 2014, could be linked to registers, responded to the surveyquestion regarding parental illness, had information from registers on relevant covariates, and had not lost a parent, resulting in a study population of 63,437 adolescents, mean age 17.7 years, range 15 to 25 years. Figure 1 illustrates the use of the data sources to answer the study aims.

\section{Measures and Variables} Parental Illness

For the register sample, we used information from the Danish National Patient Register to retrieve information about illness of legal parents. The Danish National Patient Register contains information on all diagnoses registered at both inpatient and outpatient contacts, including somatic as well as psychiatric diagnoses. Since 1994, diagnoses have been

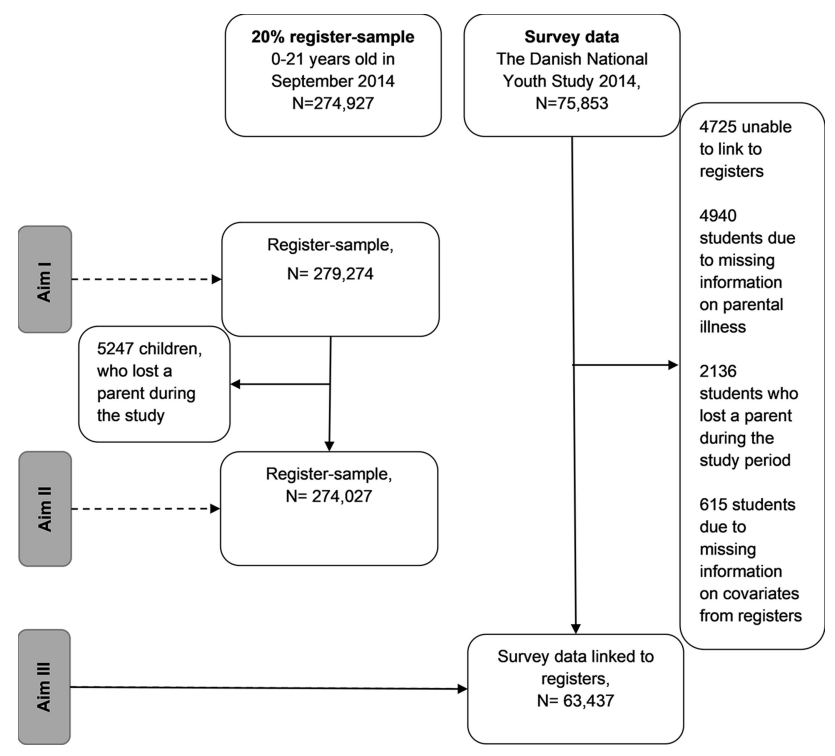

Figure I Overview of the study populations and application in relations to the study aims. registered according to ICD-10 codes. ${ }^{20}$ Prevalence of physical parental illness was defined as registration of any primary and secondary diagnoses included in the Charlson Comorbidity Index from birth of the child until September 1, 2014. The Charlson Comorbidity Index is a validated measure to predict prognostic mortality and includes 19 illness categories, see Appendix A. ${ }^{21}$ Parental mental illness was also identified using the Danish National Patient Register, and included all mental disorders, apart from ICD-10 codes of dementia (F00-F03), which are included in the Charlson Comorbidity Index. Children in the register sample were categorized as having: 1) no ill parents; 2) physically ill parent(s); 3) mentally ill parent(s); or 4) physical and mentally ill parent(s).

In the Danish National Youth Study 2014, students were asked if they had experienced serious illness or disability of a parent. The following answering categories were available: "no", "yes, within the last year", or "yes, longer time ago", dichotomized into ill parent or no ill parent. To investigate the co-occurrence of parental illness using survey and register data, a combined variable was constructed, categorizing the adolescents into: 1) no ill parents; 2) ill parent identified in registers and survey; 3) ill parent identified in register only; 4) ill parent identified in survey only.

\section{Socioeconomic, Demographic, and Health Information}

Data on parental occupation and education, migration status, family-structure, and serious or chronic medical condition of the child was retrieved from registers by September 2014. The information and registers used are displayed in Appendix B. In the analyses of study aim III, based on the Danish National Youth Study 2014 linked to registers, students with missing information on socioeconomic and demographic variables were excluded. In the $20 \%$ register-sample, missing information were handled as follows: for parental occupation and use of transfer income, children with missing information for both parents ( $\mathrm{n}=2137$ ) were coded as having 0 parents employed/ receiving transfer income. Missing information on ethnicity $(\mathrm{n}=85)$ was coded as Danish origin, and missing information for parental education and family structure is presented as unknown.

\section{Use of Primary Health Care}

Information about use of general practitioner, specialist practice, psychiatrist (private practice), and psychologist by 
parents during the year before the Danish National Youth Study 2014 took place, was retrieved from the Danish National Health Service Registry. The average number of visits to the general practitioner in 2017 was 5.6 for Danish men and 8.4 for women, whereas men on average had 0.7 contacts to a practicing specialist and women had 1.1 contacts to a practicing specialist. ${ }^{22}$ In this study general practitioner was dichotomized as $<10$ visits versus $\geq 10$ visits, as an indication of more than average use of general practitioner. Specialist practices included in this article rheumatology, internal medicine, surgery, orthopedic surgery and neurology. Practicing specialists, where the majority of patients are most likely not seriously ill, were excluded from the measure, e.g., gynecology and plastic surgery. Visits to specialist practices were dichotomized as 0 visits versus $\geq 1$ visit(s).

\section{Parental Death}

Part of the study population had lost a parent during the study period (1993-2014). Information on parental death was retrieved form the Cause of Death Register. These children are included in the estimation over overall and age-specific prevalence (Table 2). In the remainder of the article, children who have lost a parent are excluded to enable characterizing children with ill parents and distinguishing them, from children having lost a parent.

\section{Analysis}

The analyses were conducted using SAS 9.4. Prevalence of parental physical, mental, and physical and mental illness was stratified by age of the child in the following age groups: 0 - $\leq 6$ years, $6-\leq 12$ years, $12-\leq 17$ years, and 17-21 years. Characteristics of the children by September 2014, according to parental illness status, were investigated using cross tabulation and chi2-test.

Discrepancies between child-reported and register-based prevalence was investigated using cross tabulations, stratified by gender to reveal potential gender differences, as gender differences has been seen in relation to child-reported parental illness in other surveys. ${ }^{23}$ Reporting of parental illness in the survey according to specific register diagnosis was explored using cross tabulations and confidence intervals. Sensitivity analyses were performed in relation to the discrepancy between parental illness reported in the survey and identified in registers (diagnoses registered during the five years prior to the time of the survey). This was done to minimize the risk of misclassification due to the potential time gap between the diagnoses given to a parent in the registers and time of the survey.

\section{Ethics}

According to Danish law, informed consent and approval from the Ethical committee is not warranted for registerbased studies. Likewise, no formal ethical assessment or approval is needed for questionnaire-based population studies in Denmark. The study is declared to Statistics Denmark and the Research \& Innovation Organization at University of Southern Denmark (J. No.10.755).

\section{Results}

In the representative sample of Danish children aged 0-21 years old, 25.3\% were identified in the register as having a parent with a physical illness, mental illness, or mental and physical. The prevalence increased by age of the child from $12.0 \%$ among the 0 - to 6 -year-olds to $36.9 \%$ among the 17 to 21 -year-olds (Table 1). For 8742 children, diagnoses were

Table I Register-Based Prevalence of Children with an III Parent

\begin{tabular}{|l|l|l|l|l|l|}
\hline & N & No III Parents & $\begin{array}{l}\text { Physically ill } \\
\text { Parent(s) }\end{array}$ & $\begin{array}{l}\text { Mentally Illness } \\
\text { Parent(s) }\end{array}$ & $\begin{array}{l}\text { Mentally and Physically ill } \\
\text { Parent(s) }\end{array}$ \\
\hline $\mathbf{N}$ & 279,274 & 208,704 & 29,927 & 28,882 & 11,716 \\
\hline Child's age & & & & & \\
\hline All ages & & $74.7 \%$ & $10.4 \%$ & $10.7 \%$ & $4.2 \%$ \\
\hline $0-<6$ years & 63,836 & $88.0 \%$ & $3.9 \%$ & $7.3 \%$ & $0.8 \%$ \\
\hline $6-<12$ years & 79,081 & $78.0 \%$ & $8.3 \%$ & $11.0 \%$ & $2.7 \%$ \\
\hline $12-<17$ yeas & 67,456 & $70.3 \%$ & $12.2 \%$ & $12.2 \%$ & $5.3 \%$ \\
\hline $\begin{array}{l}17-<21 \\
\text { years }\end{array}$ & 68,901 & $63.1 \%$ & $16.8 \%$ & $12.2 \%$ & $7.9 \%$ \\
\hline
\end{tabular}


Table 2 Characteristics of Children without and with an III Parent Stratified by Physical and Mental Illness, Identified in Registers

\begin{tabular}{|c|c|c|c|c|c|c|}
\hline & \multirow[b]{2}{*}{$\mathbf{N}$} & \multicolumn{4}{|c|}{ Parental Illness According to Registers ${ }^{a}$} & \multirow[b]{2}{*}{$\mathrm{Chi}^{\mathrm{b}}$} \\
\hline & & $\begin{array}{l}\text { Non-Identified } \\
\mathbf{N}=\mathbf{2 0 7 , 4 2 6}\end{array}$ & $\begin{array}{l}\text { Physically } \\
\text { III } \\
N=27,046\end{array}$ & $\begin{array}{l}\text { Mentally } \\
\text { III } \\
\mathrm{N}=\mathbf{2 9 , 2 3 8}\end{array}$ & $\begin{array}{l}\text { Mentally and } \\
\text { Physically ill } \\
\mathrm{N}=10,317\end{array}$ & \\
\hline $\begin{array}{l}\text { Migration status } \\
\text { Danish origin } \\
\text { Immigrants } \\
\text { Descendants }\end{array}$ & $\begin{array}{l}243,729 \\
8435 \\
21,863\end{array}$ & $\begin{array}{l}89.7 \% \\
3.3 \% \\
7.0 \%\end{array}$ & $\begin{array}{l}87.7 \% \\
2.1 \% \\
10.2 \%\end{array}$ & $\begin{array}{l}86.8 \% \\
2.7 \% \\
10.5 \%\end{array}$ & $\begin{array}{l}82.7 \% \\
3.1 \% \\
14.2 \%\end{array}$ & $<0.0001$ \\
\hline $\begin{array}{l}\text { Family structure } \\
\text { Single-parent household } \\
\text { Two-parent household }\end{array}$ & $\begin{array}{l}61,928 \\
212,099\end{array}$ & $\begin{array}{l}18.6 \% \\
81.4 \%\end{array}$ & $\begin{array}{l}24.8 \% \\
75.2 \%\end{array}$ & $\begin{array}{l}40.5 \% \\
59.5 \%\end{array}$ & $\begin{array}{l}47.6 \% \\
52.4 \%\end{array}$ & $<0.0001$ \\
\hline Cohabiting with ill parent & - & - & $78.8 \%$ & $65.8 \%$ & $50.2 \%$ & $<0.0001$ \\
\hline $\begin{array}{l}\text { Parental education level } \\
\text { Basic school } \\
\text { Secondary school } \\
\text { Vocational educational training. } \\
\text { Higher education (short, medium, long } \\
\text { BA, PhD) } \\
\text { Unknown }\end{array}$ & $\begin{array}{l}20,841 \\
7800 \\
97,125 \\
141,385 \\
6876\end{array}$ & $\begin{array}{l}5.7 \% \\
2.7 \% \\
33.7 \% \\
55.0 \% \\
2.9 \%\end{array}$ & $\begin{array}{l}8.7 \% \\
3.0 \% \\
39.1 \% \\
48.1 \% \\
1.1 \%\end{array}$ & $\begin{array}{l}15.5 \% \\
3.8 \% \\
41.5 \% \\
37.8 \% \\
1.4 \%\end{array}$ & $\begin{array}{l}20.3 \% \\
3.8 \% \\
43.8 \% \\
31.0 \% \\
1.1 \%\end{array}$ & $<0.0001$ \\
\hline $\begin{array}{l}\text { N employed parents } \\
0 \\
1 \\
2\end{array}$ & $\begin{array}{l}24,796 \\
59,891 \\
189,340\end{array}$ & $\begin{array}{l}6.6 \% \\
18.5 \% \\
74.9 \%\end{array}$ & $\begin{array}{l}9.1 \% \\
24.0 \% \\
66.9 \%\end{array}$ & $\begin{array}{l}19.7 \% \\
36.8 \% \\
43.5 \%\end{array}$ & $\begin{array}{l}28.8 \% \\
41.3 \% \\
29.9 \%\end{array}$ & $<0.0001$ \\
\hline $\begin{array}{l}\text { N parents receiving transfer income } \\
0 \\
1 \\
2\end{array}$ & $\begin{array}{l}224,527 \\
38,545 \\
10,955\end{array}$ & $\begin{array}{l}88.3 \% \\
9.7 \% \\
2.0 \%\end{array}$ & $\begin{array}{l}78.1 \% \\
17.0 \% \\
4.9 \%\end{array}$ & $\begin{array}{l}55.7 \% \\
32.9 \% \\
11.4 \%\end{array}$ & $\begin{array}{l}39.0 \% \\
41.2 \% \\
19.8 \%\end{array}$ & $<0.0001$ \\
\hline $\begin{array}{l}\text { Register-based chronic condition (CC) } \\
\text { of the child } \\
\text { No CC } \\
\text { Physical CC } \\
\text { Mental/behavioral CC } \\
\text { Physical and mental/behavioral CC }\end{array}$ & $\begin{array}{l}218,756 \\
34,902 \\
14,212 \\
6157\end{array}$ & $\begin{array}{l}82.0 \% \\
12.2 \% \\
4.1 \% \\
1.7 \%\end{array}$ & $\begin{array}{l}75.6 \% \\
14.8 \% \\
6.4 \% \\
3.2 \%\end{array}$ & $\begin{array}{l}73.2 \% \\
13.4 \% \\
9.4 \% \\
4.0 \%\end{array}$ & $\begin{array}{l}65.7 \% \\
15.3 \% \\
12.8 \% \\
6.2 \%\end{array}$ & $<0.0001$ \\
\hline
\end{tabular}

Notes: ${ }^{a}$ Excluding children, who have lost a parent during the study period. ${ }^{\mathrm{b}}$ Chi-Square test of significant differences in the distribution of the variable across parental illness status

identified for both parents at some point during the study period, corresponding to $7.6 \%$ of the children who had a parent with a register diagnosis (data not shown). In total, 5247 children lost a parent during the study period, $75.6 \%$ of these children had a parental physical or mental diagnosis in registers (data not shown).

Table 2 shows great socioeconomic and demographic variation between children, depending on the illness status of their parent. The greatest inequality is seen for children affected by both mental and physical parental illness; a considerable higher proportion of these children experience parental unemployment, one or two parents receiving transfer income, and low parental educational level. Moreover, a substantially higher proportion of children with a mentally or mentally and physically ill parent(s) live in single-parent households. Children with a physically ill parent are also generally disadvantaged socioeconomically compared to children with no ill parents.

\section{Using Survey Data and Register Data to Identify III Parents}

A total $15.6 \%$ of the students in the survey reported serious parental illness. Among the same population of 
Table 3 Agreement Between Identification of Parental Illness in Registers and Survey, \%(n)

\begin{tabular}{|l|l|l|l|}
\hline N=63,437 & \multicolumn{2}{|l|}{$\begin{array}{l}\text { Register Identified Parental } \\
\text { Illness }\end{array}$} & \\
\hline $\begin{array}{l}\text { Survey Identified } \\
\text { Parental IIIness }\end{array}$ & Yes & No & Total \\
\hline Yes & $9.1 \%(5748)$ & $6.6 \%(4164)$ & $15.6 \%$ \\
\hline No & $20.2 \%(12,83 I)$ & $64.1 \%(40,694)$ & $84.4 \%$ \\
\hline Total & $29.3 \%$ & $70.7 \%$ & \\
\hline
\end{tabular}

15- to 25 -year-olds, $29.3 \%$ were identified in the registers as having an ill parent (Table 3). The proportion of students identified as having an ill parent in both registers and in the survey was $9 \%$, one fifth were only identified in the registers, and $6.6 \%$ self-reported parental illness, but was not identified in the registers as having an ill parent.

Table 4 shows that overall, students identified as having an ill parent, regardless of identification methods, differed from those who were not identified as having an ill parent with regards to socioeconomic characteristics and parental use of primary health care service, with minor variation between the groups of students with ill parents identified in registers and/or surveys.

A slightly higher proportion of students with parental illness identified in both registers and in the survey had two unemployed parents, low parental educational level, lived in single-parent homes, had a register-based chronic condition, and had parents with at least ten visits at the general practitioner during the last year, compared to students with no ill parents and students with only a register or a survey identified ill parent (Table 4).

Overall, a slightly higher proportion of the parents with diagnoses identified in the register was reported as seriously ill by female respondents in the survey than by male respondents (Figure 2). Only $24.5 \%$ and $30.2 \%$ of the male and female respondents, respectively, identified as having a mentally ill parent in the registers, reported serious parental illness in the survey. Among the physical diagnoses, the lowest agreement was seen for chronic pulmonary disease (male: $20.8 \%$; female: $24.9 \%$ ), and the highest

Table 4 Characteristic of Adolescents from the Danish National Youth Study, According to Identification of Parental Illness in Registers and in Survey

\begin{tabular}{|c|c|c|c|c|}
\hline & \multicolumn{4}{|l|}{ Parental Illness } \\
\hline & $\begin{array}{l}\text { Non-Identified } \mathrm{N}=40,694 \\
\text { (64.1\%) }\end{array}$ & $\begin{array}{l}\text { In Registers and } \\
\text { Survey } \\
\text { N=5748 (9.1\%) }\end{array}$ & $\begin{array}{l}\text { In Registers } \\
\text { Only } \\
N=|2,83| \\
(20.2 \%)\end{array}$ & $\begin{array}{l}\text { In Survey } \\
\text { Only } \\
N=4164 \\
(6.6 \%)\end{array}$ \\
\hline \multicolumn{5}{|l|}{ Migration status } \\
\hline Danish & $93.8 \%$ & $89.6 \%$ & $86.9 \%$ & $91.8 \%$ \\
\hline Immigrants & $1.7 \%$ & $2.6 \%$ & $3.3 \%$ & $2.7 \%$ \\
\hline Descendants & $4.6 \%$ & $7.9 \%$ & $9.9 \%$ & $5.5 \%$ \\
\hline \multicolumn{5}{|l|}{ Parental education level } \\
\hline Basic school & $2.9 \%$ & $6.8 \%$ & $5.7 \%$ & $4.2 \%$ \\
\hline Secondary school & $2.2 \%$ & $3.4 \%$ & $3.1 \%$ & $2.9 \%$ \\
\hline Vocational educational training & $30.3 \%$ & $34.8 \%$ & $34.3 \%$ & $34.2 \%$ \\
\hline Higher education (short, medium, long BA, PhD) & $64.6 \%$ & $55.1 \%$ & $56.9 \%$ & $58.6 \%$ \\
\hline \multicolumn{5}{|l|}{$\mathbf{N}$ employed parents } \\
\hline 0 & $2.1 \%$ & $11.2 \%$ & $8.4 \%$ & $5.4 \%$ \\
\hline 1 & $12.3 \%$ & $35.8 \%$ & $24.5 \%$ & $27.6 \%$ \\
\hline 2 & $85.6 \%$ & $52.9 \%$ & $67.1 \%$ & $66.9 \%$ \\
\hline \multicolumn{5}{|l|}{$\begin{array}{l}\text { Parental use of primary health care services in } \\
\text { the last year }\end{array}$} \\
\hline$\geq 10$ visits to the general practitioner & $43.8 \%$ & $71.6 \%$ & $61.9 \%$ & $62.5 \%$ \\
\hline$\geq I$ visits(s) to a specialist practice & $26.5 \%$ & $32.6 \%$ & $32.1 \%$ & $30.5 \%$ \\
\hline$\geq I$ visits(s) to a psychologist & $7.4 \%$ & $17.8 \%$ & $13.8 \%$ & $14.6 \%$ \\
\hline$\geq$ I visits(s) to a psychiatrist & $2.7 \%$ & $11.8 \%$ & $10.2 \%$ & $5.9 \%$ \\
\hline
\end{tabular}




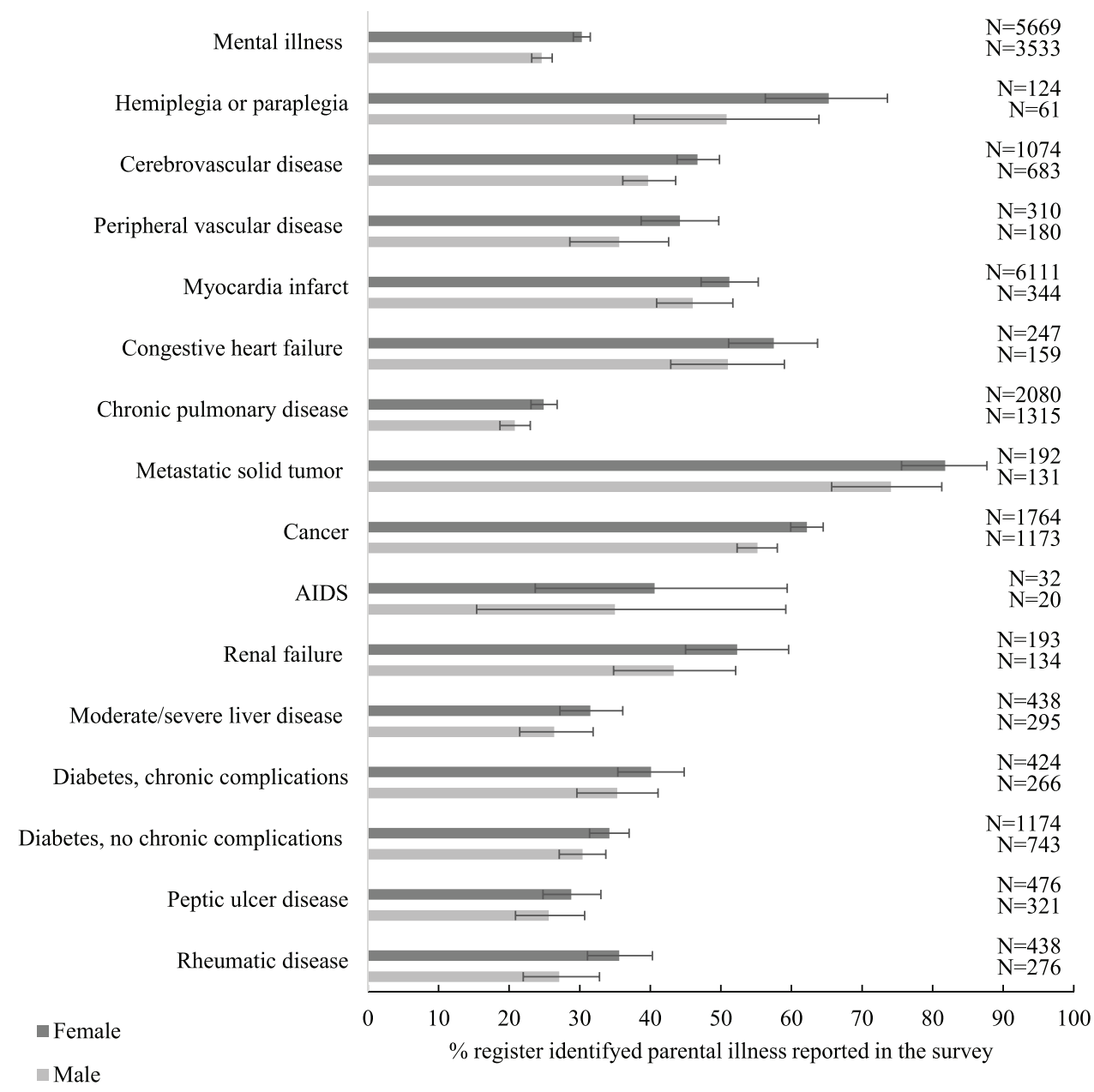

Figure 2 Proportion and 95\% confidence intervals of the register-identified parental illness reported by students in the Danish National Youth Study 20I4, by diagnosis and gender of the adolescent.

Abbreviation: $\mathrm{Cl}$, confidence interval.

was seen for metastatic solid tumors (male: 74.1\%; female: $81.8 \%$ ), and cancer (male: $55.2 \%$; female: $62.2 \%$ ).

Among the students with a survey-reported parental illness who were not identified in the registers as having an ill parent with a mental diagnosis (ICD-10 F-diagnosis) or a diagnoses included in the Charlson Comorbidity Index, $92.6 \%$ had another parental diagnosis in the registers (data not shown). These diagnoses included a broad range of illnesses, but no pattern or single diagnoses were identified as the reason for the reported parental illness in the survey.

\section{Sensitivity Analyses}

Sensitivity analyses were performed in relation to characterization of children with and without a parent with a register diagnosis using a data sample which excluded children with missing information on the socioeconomic and demographic variables. In total 6931 children were excluded. This resulted in minimal changes in the distributions of the socioeconomic and demographic variables in relation to parental illness status.

To investigate how the time span between a register diagnose and completion of the survey may influence the findings, analyses only including diagnoses registered during the five years prior to the time of the survey were conducted. This resulted in a decrease of the proportion identified in both registers and in the survey from $9.1 \%$ to $6.0 \%$. The proportion only identified in registers, as having an ill parent, was reduced from $20.2 \%$ to $9.3 \%$. The proportion of students only identified in the survey increased from $6.6 \%$ to $9.6 \%$ (data not shown).

\section{Discussion}

Of the total study sample consisting of 0 - to 21-year-olds, $25.3 \%$ had a register-identified ill parent. The estimated 
prevalence of parental physical illness in this study was $10.3 \%, 14.5 \%$ including those with both a mental and physical parental diagnosis, which is markedly higher than the questionnaire-based estimate by Barkmann et al 2007. ${ }^{8}$ The overall prevalence of parental mental illness of $14.9 \%$ is however noticeably lower than estimated in previous register-based studies. ${ }^{10,24}$ This might be due to variations in the registration practice of mental illness between countries and discrepancies in the definition of parental mental illness between studies, as previous studies also included information about hospitalizations, prescription of psychotropic medications and referral to psychiatric care, whereas we only included diagnoses. ${ }^{9,10}$ In Denmark, mild and moderate mental illnesses are often treated by the general practitioners or private practicing psychiatrist and not registered in the Danish National Patient Register, thus moderate mental illness of a parent is probably not include in the estimated prevalence. ${ }^{25}$

Children with an ill parent were characterized by poor socioeconomic background, single-parent family structure, and a higher prevalence of chronic conditions of the child, compared to children without an ill parent. The elevated frequency of low parental educational level among children with a physically ill parent is contrary to findings from other Danish register studies. ${ }^{13,26}$ Joergensen et al (2018) found significantly higher parental educational levels among children with parental cancer, whereas Moberg et al (2016) found no difference in parental education level among children with parental multiple sclerosis. ${ }^{13}$ This could be due to variation in social inequality of incidence between different somatic illnesses. For instance, a Danish report on social inequality in health showed no socioeconomic differences in the occurrence of several cancer types and high inequality in incidence of chronic obstructive pulmonary disease. ${ }^{27}$ Moreover, it should be noted, that the sample in the Danish Youth Study 2014 is dominated by high school students, representing a selected and more advantaged population in relation to socioeconomic background than the general population; thus, the disease pattern of the parents in the study sample may be different than in the general population.

Using survey data from parents and adolescents, Sieh et al 2013 found, in line with this study, lower parental employment rates among children with chronically ill parents, but no difference in relation to parental education level, ${ }^{12}$ possibly due to selection bias.
The socioeconomic disadvantage of children with parental mental illness is in compliance with previous findings, ${ }^{14,15}$ underlining the vulnerability of this group of children. The elevated frequency of mental/behavioral conditions among children with a mentally or mentally and physically ill parent is in line with Thorup et al (2018) who found an increased risk of mental illness in childhood and adolescence, when a parent had a serious mental disorder. ${ }^{28}$

To our knowledge, this study is the first to explore the use of different data sources in the identification of serious parental illness. We found discrepancies between parental illness identified using survey data and register data. Using survey data, the prevalence of serious parental illness was $15.6 \%$, whereas the register prevalence of parental illness for the same populations of 15- to 25-year-olds was $29.3 \%$. The proportion identified as having a seriously ill parent in survey and in the register was $9 \%$. Sensitivity analyses, using only the most recent diagnoses in registers (five years), reduced the discrepancy in relation to those only identified in the registers, however increased the proportion identified only in the survey. This might indicate that some parents with a register diagnosis have recovered and are not regarded ill by the adolescent. The agreement between register identified and survey reported parental illness varied across diagnoses. Overall, female respondents were slightly more likely to report parental illness than male respondents. Among adolescents identified in the registers as having a parent with a mental illness, only $30.3 \%$ and $24.6 \%$ of female and male respondents, respectively, reported parental illness in the survey. The phrasing of the question in the survey, asking about "serious illness of a parent," might not apply very well to mental illness and could have resulted in an underestimation of mental illness. Moreover, some adolescents may not have recognized their parent as being mentally ill, were not informed about the illness, or did not wish to report the illness due to potential shame and the taboo related to mental illness. ${ }^{29-31}$ These issues are likely to have resulted in misclassification and thus an underestimation of parental mental illness based on survey data. For the physical illnesses identified in the registers the agreement with survey data varied greatly; from $20.8 \%$ studentreported parental illness among male respondents with a parental register diagnosis of chronic pulmonary disease to $81.8 \%$ of the female respondents with a parental register diagnosis of metastatic solid tumor, reporting parental illness in the survey. The identification of parental illness among students who did not report parental illness in the 
survey, may be explained by the potential timespan from parental diagnosis in the register to data collection of the Danish National Youth Study 2014, as the parent may have recovered. Moreover, great variation in the severity within a diagnosis exist. For instance, diabetes may in some cases be considered serious by the adolescent, but may in many cases not be, and thus will not be reported in the survey but will be included in the register prevalence of parental illness.

Students who reported parental illness in the survey, but were not initially identified in the registers, overall differed from students with no ill parent and were similar to students with parental illness identified in the registers in relation to socioeconomic and demographic characteristics and parental use of primary health care services, indicating that these students do have an ill parent. Looking into parental diagnoses in the registers, which was not part of the Charlson Comorbidity Index or a mental diagnosis, we recognized no patterns or clusters of diagnoses, suggesting that these students have parents with rare illnesses or illnesses treated in the primary sector.

\section{Strengths and Limitations}

One of the strengths in using register data to identify parental illness and characterize children with an ill parent, is the representativity gained in registers. Moreover, the Danish registers generally have high validity and completeness, and register data is moreover not influenced by nondisclosure or recall bias by the study population. ${ }^{32}$ There are some limitations in the use of registers for the purpose of identifying parental illness. The register identified parental illness is based solely on diagnoses, not taking account of the severity, duration, or degree of impairment in every-day life caused by the illness. Also, only diagnoses applied in hospitals are included, while diagnoses applied by specialists or general practitioners are not registered. Another limitation is the use of Charlson Comorbidity Index to identify parental physical illness in the registers. The Charlson Comorbidity Index was not developed for the purpose of identifying diagnosis relevant for the well-being of the patients' offspring. However, to our knowledge no classification of serious or chronic somatic parental illness exists. In a recent Danish register study, diagnoses in the Charlson Comorbidity Index have been used to identify lifethreatening parental illness. ${ }^{33}$ In relation to the characteristics of children with an ill parent, including parental illness from birth of the child to September 1st 2014 may result in misclassification of some children, who have been identified as having an ill parent early in childhood, however the diagnosis might not be relevant by the time of characterization in 2014.

In the survey, the measure of parental illness involves a subjective judgement and evaluation by the adolescent of when a parent is seriously ill, relying on an individual reference point. However, a self-reported measure is more likely to capture illness affecting the everyday life of the child than a parental illness measure based solely on a hospital diagnosis. ${ }^{34}$ A limitation of the Danish National Youth Study 2014 is the lack of representativity of the general population. The survey included predominately students attending high school, with an underrepresentation of adolescents attending vocational education and not including adolescents outside of the educational system.

The opportunity to link a large survey sample including child-reported parental illness with register information on parental diagnoses provides a unique opportunity to study discrepancies between the two data sources.

\section{Conclusions and Implications}

This study confirms that a substantial proportion of Danish children have a parent with a serious mental or physical diagnosis. These children are characterized by lower socioeconomic position, single-parent households, and higher frequency of mental/behavioral and physical chronic conditions among the children. The findings in our study underline that children experiencing parental illness are likely also to be socioeconomically disadvantaged, increasing their vulnerability and calling for targeted initiatives to support these families and children.

Using register data and survey data to identify parental illness revealed very different results. The parental use of primary health care services and characteristics of adolescents identified in either the survey or the register as having an ill parent, indicate that parental illness identified using either method do indeed capture ill parents, but may not capture all cases. Moreover, the results suggest difficulties in asking adolescents about parental mental illness, possibly due to the stigma and lack of knowledge related to mental illness. $^{29}$ Asking more directly about parental mental illness in a survey, rather than asking about serious parental illness in general, might improve the accuracy of this measure. To improve the register-based measure of serious parental illness as a risk factor of well-being of the child could be done by evaluating the potential impact on the children for every diagnosis, combining information about diagnosis, number 
and duration of hospitalization, and records from Danish National Prescription Registry.

\section{Acknowledgments}

This article is part of the $\mathrm{PhD}$ thesis by the first author and a summary of the results are presented in the $\mathrm{PhD}$ thesis. ${ }^{35}$

\section{Disclosure}

The authors report no conflicts of interest in this work.

\section{References}

1. Wittenberg E, Saada A, Prosser LA. How illness affects family members: a qualitative interview survey. Patient-Centered Outcomes Res. 2013;6(4):257-268. doi:10.1007/s40271-013-0030-3

2. Romer G, Barkmann C, Schulte-Markwort M, Thomalla G, Riedesser P. Children of somatically ill parents: a methodological review. Clin Child Psychol Psychiatry. 2002;7(1):17-38. doi:10.1177/ 1359104502007001003

3. Sieh DS, Meijer AM, Oort FJ, Visser-Meily JMA. Problem behavior in children of chronically ill parents: a meta-analysis. Clin Child Fam Psychol Rev. 2010;13(4):384-397. doi:10.1007/s10567-010-0074-z

4. Steck B, Grether A, Amsler F, et al. Disease variables and depression affecting the process of coping in families with a somatically ill parent. Psychopathology. 2007;40(6):394-404. doi:10.1159/000106470

5. Harrison L, Harrington R. Adolescents' bereavement experiences. Prevalence, association with depressive symptoms, and use of services. Journal of Adolescence. 2001;24(2):159-169. doi:10.1006/ jado.2001.0379

6. Stikkelbroek Y, Bodden DHMM, Reitz E, et al. Mental health of adolescents before and after the death of a parent or sibling. Eur Child Adolesc Psychiatry. 2016;25(1):49-59. doi:10.1007/s00787015-0695-3

7. Niemelä M, Paananen R, Hakko H, Merikukka M, Gissler M, Räsänen S. The prevalence of children affected by parental cancer and their use of specialized psychiatric services: the 1987 Finnish Birth Cohort study. Int $J$ Cancer. 2012;131(9):2117-2125. doi:10.1002/ijc. 27466

8. Barkmann C, Romer G, Watson M, Schulte-Markwort M. Parental physical illness as a risk for psychosocial maladjustment in children and adolescents: epidemiological findings from a national survey in Germany. Psychosomatics. 2007;48(December):476-481. doi:10.1176/appi.psy.48.6.476

9. Bortes C, Strandh M, Nilsson K. Parental illness and young people's education. Child Indic Res. 2020;13(6):2069-2091. doi:10.1007/ s12187-020-09731-x

10. Abel KM, Hope H, Swift E, et al. Prevalence of maternal mental illness among children and adolescents in the UK between $<\mathrm{Y}>2005$ and 2017: a national retrospective cohort analysis. Lancet Public Heal. 2019;4(6):e291-e300. doi:10.1016/S2468-2667(19)30059-3

11. Stambaugh LF, Forman-Hoffman V, Williams J, et al. Prevalence of serious mental illness among parents in the United States: results from the National Survey of Drug Use and Health, 2008-2014. Ann Epidemiol J. 2017;27(3):222-224. doi:10.1016/j.annepidem.2016.12.005

12. Sieh DS, Visser-Meily JMA, Meijer AM. Differential outcomes of adolescents with chronically ill and healthy parents. J Child Fam Stud. 2013;22:209-218. doi:10.1007/s10826-012-9570-8

13. Moberg JY, Magyari M, Koch-Henriksen N, Thygesen LC, Laursen B, Soelberg Sørensen P. Educational achievements of children of parents with multiple sclerosis: a nationwide register-based cohort study. J Neurol. 2016;263:2229-2237. doi:10.1007/s00415016-8255-4
14. Davidsen KA, Christiansen E, Haubek D, et al. Parental mental illness, attendance at preventive child healthcare and dental caries in the offspring: a nation-wide population-based cohort study. Soc Psychiatry Psychiatr Epidemiol. 2020;1. doi:10.1007/s00127-02001936-3

15. Van Loon LMA, Van de Ven MOM, Van Doesum KTM, Witteman CLM, Hosman CMH. The relation between parental mental illness and adolescent mental health: the role of family factors. J Child Fam Stud. 2014;23(7):1201-1214. doi:10.1007/s10826-0139781-7

16. Van Oostrom SH, Gijsen R, Stirbu I, et al. Time trends in prevalence of chronic diseases and multimorbidity not only due to aging: data from general practices and health surveys. Published Online. 2016. doi:10.1371/journal.pone. 0160264

17. Pisinger V, Mikkelsen SS, Bendtsen P, Egan KK, Tolstrup JS. The Danish National Youth Study 2014: study design, population characteristics and non-response analysis. Scand J Public Health. 2020;48:224-232. doi:10.1177/1403494817729283

18. Thygesen LC, Daasnes C, Thaulow I, Brønnum-hansen H. Introduction to Danish (nationwide) registers on health and social issues: structure, access, legislation, and archiving. Scand J Public Health. 2011;39(7):12-16. doi:10.1177/1403494811399956

19. Pedersen CB. The Danish Civil Registration System. Scand J Public Health. 2011;39(7):22-25. doi:10.1177/1403494810387965

20. Schmidt M, Schmidt SAJ, Sandegaard JL, Ehrenstein V, Pedersen L, Sørensen HT. The Danish National Patient Registry: a review of content, data quality, and research potential. Clin Epidemiol. 2015;7:449-490. doi:10.2147/CLEP.S91125

21. Charlson ME, Pompei P, Ales KL, MacKenzie CR. A new method of classification of prognostic comorbidity for longitudinal studies: development and validation. $J$ Chron Dis. 1987;5:373-383. doi:10.1016/0021-9681(87)90171-8

22. Statistik D. Kvinder bruger e-konsultation mere end mænd. Nyt Fra Danmarks Stistisk. 2018. Available from: https://www.dst.dk/Site/ Dst/Udgivelser/nyt/GetPdf.aspx?cid=27034. Accessed March 4, 2021.

23. Jørgensen SE, Andersen A, Lund L, Due P, Michelsen SI. Trivsel Og Hverdagsliv Blandt Børn Og Unge Som Pårørende Og Efterladte Statens Institut for Folkesundhed. Statens Institut for Folkesundhed, Syddansk Universitet; 2019.

24. Maybery DJ, Reupert AE, Patrick K, Goodyear M, Crase L. Prevalence of parental mental illness in Australian families. Psychiatr Bull. 2009;33:22-26. doi:10.1192/pb.bp.107.018861

25. Mors O, Perto GP, Mortensen PB. The Danish psychiatric central research register. Scand J Public Health. 2011;39(7):54-57. doi: $10.1177 / 1403494810395825$

26. Joergensen AC, Kjaer Urhoj S, Nybo Andersen A-M. Primary school achievement and socioeconomic attainment in individuals affected by parental cancer in childhood or adolescence: a Danish nationwide register-based study. J Epidemiol Community Health. 2018:1-8. doi:10.1136/jech-2018-210472

27. Udesen CH, Skaarup C, Petersen MNS, Ersbøll AK. Social Ulighed I Sundhed Og Sygdom. Udviklingen I Danmark I Perioden 2010-2017. 2020.

28. Thorup AAE, Laursen TM, Munk-Olsen T, et al. Incidence of child and adolescent mental disorders in children aged 0-17 with familial high risk for severe mental illness-A Danish register study. Schizophr Res. 2018;197:298-304. doi:10.1016/j.schres.2017.11.009

29. Gladstone BM, Boydell KM, Seeman MV, Mckeever PD. Children's experiences of parental mental illness: a literature review. Early Interv Psychiatry. 2011;5(4):271-289. doi:10.1111/j.17517893.2011.00287.x

30. Yamamoto R, Keogh B. Children's experiences of living with a parent with mental illness: a systematic review of qualitative studies using thematic analysis. J Psychiatr Ment Health Nurs. 2018;25 (2):131-141. doi:10.1111/jpm.12415 
31. Vendsborg P, Nordentoft M, Lindhardt A. Stigmatisering af mennesker med psykisk lidelse. Ugeskr Laeger. 2011;173(16):1194-1198.

32. Thygesen LC, Ersbøll AK. When the entire population is the sample: strengths and limitations in register-based epidemiology. Eur J Epidemiol. 2014;29(8):551-558. doi:10.1007/s10654-013-9873-0

33. Rod NH, Bengtsson J, Budtz-Jørgensen E, et al. Trajectories of childhood adversity and mortality in early adulthood: a population-based cohort study. Lancet. 2020;396(396):489-497. doi:10.1016/S0140-6736(20)30621-8
34. Stoeckel M, Weissbrod C. Growing up with an ill parent: an examination of family characteristics and parental illness features. Fam Syst Heal. 2015;33(4):356-362. doi:10.1037/fsh0000140

35. Jørgensen SE. Parental Illness in Adolescence: the Role of a Supportive Environment. 2020. doi:10.21996/rv2a-z021

\section{Publish your work in this journal}

Clinical Epidemiology is an international, peer-reviewed, open access, online journal focusing on disease and drug epidemiology, identification of risk factors and screening procedures to develop optimal preventative initiatives and programs. Specific topics include: diagnosis, prognosis, treatment, screening, prevention, risk factor modification,

Submit your manuscript here: https://www.dovepress.com/clinical-epidemiology-journal systematic reviews, risk \& safety of medical interventions, epidemiology \& biostatistical methods, and evaluation of guidelines, translational medicine, health policies \& economic evaluations. The manuscript management system is completely online and includes a very quick and fair peer-review system, which is all easy to use. 